\title{
The efficacy of selective laser trabeculoplasty versus argon laser trabeculoplasty in pseudophakic glaucoma patients
}

This article was published in the following Dove Press journal:

Clinical Ophthalmology

21 November 2012

Number of times this article has been viewed

Eldar Rosenfeld

Gabi Shemesh

Shimon Kurtz

Department of Ophthalmology, Tel-Aviv Sourasky Medical Center, Sackler Faculty of Medicine, Tel Aviv University, Tel Aviv, Israel
Correspondence: Eldar Rosenfeld Department of Ophthalmology, Tel Aviv Sourasky Medical Center, 6 Weizman

Street, Tel-Aviv 64239, Israel

Tel +97236973408

Fax+97236973867

Email eldarros@gmail.com
Introduction: This study evaluated and compared the efficacy of selective laser trabeculoplasty (SLT) and argon laser trabeculoplasty (ALT) in terms of intraocular pressure (IOP)-lowering effects in pseudophakic patients at various time points after treatment. The primary aim was to compare the efficacy of SLT and ALT in reducing the IOP of pseudophakic glaucoma patients who recently underwent successful cataract extraction surgery. The secondary endpoint was to determine the percentage of SLT and ALT patients whose IOP was successfully reduced by at least $15 \%$ from baseline.

Patients and methods: This study was a follow-up of a prospective randomized clinical trial. Fifty-two eyes from 52 glaucoma patients with uncontrolled IOP who had previously undergone successful phacoemulsification-assisted cataract excision surgery with intracapsular lens implantation were randomly assigned to treatment with either ALT $(n=30)$ or SLT $(n=22)$. Fifteen patients were excluded due to adverse events encountered during the study, leaving a total of 18 and 19 patients in the ALT and SLT groups, respectively. IOP measurements were carried out at scheduled intervals until 12 months post-laser treatment.

Results: There were no significant differences in the IOP-lowering effects between the two methods at any time point during the follow-up period. The greatest differences between the two groups were observed at 1 week posttreatment and at the 3-month time point, but neither reached a level of significance. At the final checkup, the mean IOP reduction from baseline was $3.23 \mathrm{mmHg}$ in the ALT group and $4.30 \mathrm{mmHg}$ in the SLT group $(P=0.269)$. At that visit, six $(35.3 \%)$ patients in the ALT group and $15(75 \%)$ patients in the SLT group had a reduction of $\geq 15 \%$ from their baseline IOP.

Conclusion: SLT and ALT are equally effective in their IOP-lowering capabilities in new pseudophakic glaucoma patients during the first 12 months after treatment.

Keywords: selective laser trabeculoplasty, argon laser trabeculoplasty, intraocular pressure, cataract extraction, pseudophakic glaucoma patients

\section{Introduction}

Wise and Witter ${ }^{1}$ were the first to describe the use of argon laser trabeculoplasty (ALT) for reducing intraocular pressure (IOP) in glaucoma patients. Many studies have since shown the benefit of ALT as either the initial approach for primary open angle glaucoma, or as an adjuvant to hypotensive medications. Latina and Park ${ }^{2}$ later reported a neodymium: yttrium aluminum garnet laser $(\mathrm{Q}$ switched, frequency doubled, $532 \mathrm{Nd}$ :YAG laser) that selectively targets the pigmented trabecular meshwork (TM) cells as an alternative to ALT. ${ }^{3}$ The selective laser trabeculoplasty (SLT) approach uses a few thousand times less energy than is needed by ALT, thereby maintaining 
the normal TM architecture and allowing the procedure to be repeatable. ${ }^{4}$ Several published studies that were conducted over the past few years compared the efficacy of the two methods in their ability to reduce IOP. They all showed that SLT and ALT are similar in their biological effects, complication rates, and capabilities in their IOP reduction potential among the investigated patient groups. ${ }^{5-11}$ A number of publications that reported the effect of prior cataract surgery on long-term outcomes demonstrated that clear cornea phacoemulsification carried out in normal subjects ${ }^{12-15}$ as well as in primary open-angle glaucoma (POAG) patients prior to cataract surgery ${ }^{16-18}$ significantly reduces the IOP for a sustained period of time through a mechanism not fully understood. In 2007, Werner et $\mathrm{al}^{19}$ compared the outcome of SLT as a secondary treatment for glaucoma in pseudophakic versus phakic patients and found no significant difference between phakic and pseudophakic eyes in terms of decreased IOP or success rates at any time point.

The aim of the current study was to compare the efficacy of SLT and ALT in reducing the IOP of pseudophakic glaucoma patients who recently underwent successful cataract extraction surgery. Towards that end, we evaluated and compared the IOP-lowering effect of SLT versus ALT at 12 months by determining the percentage of patients from each group that had reached a reduction of $\geq 15 \%$ in IOP from baseline.

\section{Patients and methods}

Approval was obtained from the local institutional review board (Helsinki committee). All participants signed an informed consent form before enrollment into this prospective, randomized, controlled single center trial.

All the IOP measurements, laser treatments, and follow-up evaluations were conducted by a single glaucoma specialist. The patients had been diagnosed as having either POAG, pseudoexfoliation glaucoma, pigmentary glaucoma, or ocular hypertension (OHT) (Table 1$)$. They were all receiving maximum tolerated glaucoma medical treatment and had an uncontrolled IOP of $\geq 20 \mathrm{mmHg}$. The primary outcome of this study was the IOP-lowering effect of SLT compared to ALT at 12 months. The secondary outcome was to obtain IOP measurements at 1 week and 1, 3, and 6 months following each procedure. Surgical success was defined as having reached a decrease of $\geq 15 \%$ in IOP from baseline by the time of the final follow-up at the first postoperative year.

Each patient was randomly assigned to receive either the SLT or ALT treatment according to a note that was written, which specified the name of the designated treatment, and
Table I Basic characteristics

\begin{tabular}{llll}
\hline & $\begin{array}{l}\text { ALT number } \\
\text { of eyes = 30 }\end{array}$ & $\begin{array}{l}\text { SLT number } \\
\text { of eyes = 22 }\end{array}$ & P-value \\
\hline Mean age (years) & 71.90 & 71.95 & 0.981 \\
Baseline IOP pre-laser & 25.73 & 25.63 & 0.876 \\
Sex (M/F) & $14 / 16$ & $1 \mathrm{I} / \mathrm{I}$ I & \\
Treated eye (OD/OS) & $16 / 14$ & $10 / 12$ & \\
PXFG & 8 & 7 & \\
Pigmentary glaucoma & $\mathrm{I}$ & 2 & \\
POAG & 14 & 9 & \\
OHT & 7 & 4 & \\
Mild glaucoma & 6 & 4 & \\
Moderate glaucoma & 14 & 8 & \\
Severe glaucoma & 10 & & \\
\hline
\end{tabular}

Abbreviations: ALT, argon laser trabeculoplasty; SLT, selective laser trabeculoplasty; IOP, intraocular pressure; $M$, male; F, female; OD, oculus dexter (right eye); OS, oculus sinister (left eye); PXFG, pseudoexfoliation glaucoma; POAG, primary open-angle glaucoma; $\mathrm{OHT}$, ocular hypertension.

which was placed in an unmarked and closed envelope. The inclusion criteria for the study were: being older than 18 years of age; having a history of glaucoma with subtypes POAG, pseudoexfoliation glaucoma, pigmentary glaucoma, or OHT; patients who underwent a successful phacoemulsificationassisted cataract excision surgery with intracapsular lens implantation; and patients who underwent a laser treatment (SLT or ALT) not less then 3 months and not more then 6 months following the cataract surgery. The reason for performing the laser treatment less than 3 months since the cataract extraction phacoemulsification was to allow for complete healing, such as intracapsular fibrosis and reduction in inflammatory response. This interval would also enable the achievement of a stability in change of anterior chamber depth, an angle opening distance at $500 \mu \mathrm{m}$ anterior to the scleral spur, and reduction in IOP at various time points $(1,3$, and 6 months) after cataract extraction, as shown by various studies, such as the one by Huang et al. ${ }^{20}$

Excluded from the study were patients who had a complicated cataract excision surgery; those with an intraocular lens implantation other than an intracapsular lens; an advanced visual field defect within $10^{\circ}$ of fixation; previous glaucoma surgery (except for peripheral iridotomy or ALT); previous SLT; severe corneal disease that resulted in inaccurate applanation measurements, or that inhibited the adequate visibility of the TM on gonioscopy; patients using systemic steroids; and/or patients suffering from endophthalmitis or uveitic glaucoma.

A calibrated Goldmann applanation tonometer was used for the baseline IOP measurement, which was done approximately 1 hour prior to initiating the chosen laser treatment. The follow-up schedule thereafter was as follows: 1 hour, 
1 week, and 1, 3, 6, and 12 months postlaser treatment. Changes in IOP and significance of the differences in values were determined for each time point during the follow up period of up to 12 months. Success was defined as achieving a $\geq 15 \%$ decrease of IOP from baseline. The average decreases in IOP for each group at each time point were compared statistically.

Ocular assessment included corrected visual acuity, slit-lamp assessment of the anterior segment, and gonioscopy. TM pigmentation was graded according to a standard scale from 0 to $4+$, where 0 indicated no pigmentation and $4+$ indicated dense homogeneous pigmentation. IOP was measured with a Goldmann applanation tonometer on approximately the same time of day (plus or minus 1 hour) at all follow-up visits to minimize diurnal variations of IOP. Stereoscopic optic nerve examination was performed with a Volk 90D lens (Volk Optical, Inc, Mentor, OH). On the day of laser trabeculoplasty, IOP was measured, and one drop of $1 \%$ apraclonidine was instilled in the study eye, after which either SLT or ALT was undertaken.

Laser treatment was performed at $180^{\circ}$ of the trabecular meshwork. ALT was performed using 50 applications of a $50 \mu \mathrm{m}$ spot size with a 0.1 second duration, and an average power ranging from 400 to $600 \mathrm{~mW}$ directed through a Volk magna view lens (Volk Optical, Inc) to produce blanching or an occasional bubble formation in the anterior TM. SLT was performed with a Laserex Solo (Ellex Medical Pty, Adelaide, SA, Australia) Q switched, frequency doubled, $532 \mathrm{Nd}$ :YAG laser using 50-70 nonoverlapping applications, with a spot size of $400 \mu \mathrm{m}$ (centered on the TM) and a pulse duration of $3 \mathrm{~ns}$. The initial energy used was $0.8 \mathrm{~mJ}$, which was increased or decreased until a bubble formation appeared, when it was then decreased by $0.1 \mathrm{~mJ}$ for the remainder of the treatment. The average power during treatment ranged from 0.8 to $1.2 \mathrm{~mJ}$. The IOP of the treated eye was measured 1 hour after treatment.

Patients were instructed to instill dexamethasone in the treated eye three times a day for 7 days after treatment. An attempt was made to keep the patient on the same glaucoma medications throughout the study, and the medications were changed only if the pressure worsened significantly from the preoperative status, or if there had not been an adequate drop in IOP to reach the target IOP as determined by the severity of the cup-to-disc ratio, and/or worsening of glaucomatous visual field defects and its parameters before treatment. Trabeculectomy was usually performed if the IOP had not been successfully lowered to the target pressure. This was regarded as treatment failure, and the subject's data were excluded from analysis.

\section{Results}

Fifty-two patients were enrolled in the study and randomly assigned to one of the two laser treatment procedures. Twenty-two patients were assigned to undergo SLT and 30 were assigned to undergo ALT (one of the latter patients had already undergone an ALT procedure). Table 1 summarizes the baseline characteristics of the patients, baseline IOPs, types and severity of the glaucoma based on IOP values, severity of visual field defects, and cup-to-disc ratio severity. Statistical analysis was done using $t$-test analysis. Differences were considered significant at $P<0.05$.

There were no significant differences in IOP-lowering effects between the two groups throughout the 12-month study period. Table 2 and Figure 1 display the records of the mean IOP values of the patients in the two groups during the entire follow-up period. Differences in IOP-lowering values were observed twice during the follow-up period, although neither reached a level of significance. The biggest difference in the IOP-lowering effect between the groups was observed 1 week postoperatively, where the mean IOP in the ALT group was $22.66 \mathrm{mmHg}$ and the mean IOP of the SLT group was $21.26 \mathrm{mmHg}(P=0.072)$. At the 3 -month checkup, the mean IOP in the ALT group was $22.25 \mathrm{mmHg}$ and the mean IOP in the SLT group was $20.93 \mathrm{mmHg}(P=0.069)$. At the final checkup, which was reached by 17 of $30(56.6 \%)$ patients from the ALT group and 16 of $22(72.2 \%)$ patients from the SLT group, the mean IOP reduction from baseline was $3.23 \mathrm{mmHg}$ in the ALT group and $4.30 \mathrm{mmHg}$ in the SLT group $(P=0.269)$. At the final checkup, six of the $17(35.3 \%)$ patients in ALT group and 12 of the $16(75 \%)$ patients in the SLT group had a reduction of $\geq 15 \%$ from baseline IOP (the target IOP). At 12 months, the average reduction in IOP was $12.8 \%$ in the ALT group and $16.9 \%$ in the SLT group. By reaching $\mathrm{a} \geq 15 \%$ reduction in IOP from baseline, which was

Table 2 Mean intraocular pressure after treatment

\begin{tabular}{lllll}
\hline Time point & ALT $( \pm$ SD) & SLT $( \pm$ SD) & $\begin{array}{l}\text { Total } \\
\text { patients } \\
(S L T \text { and }\end{array}$ & P-value* \\
& & & $\begin{array}{l}\text { ALT) }(\mathbf{n}) \\
\end{array}$ \\
\hline Baseline & $25.11 \pm 2.16$ & $25.36 \pm 1.83$ & 37 & 0.898 \\
I hour & $23.94 \pm 1.98$ & $23.73 \pm 2.15$ & 37 & 0.763 \\
I week & $22.66 \pm 2.24$ & $21.26 \pm 2.35$ & 37 & 0.072 \\
I month & $22.31 \pm 1.66$ & $21.05 \pm 2.65$ & 33 & 0.117 \\
3 months & $22.25 \pm 1.80$ & $20.93 \pm 2.11$ & 32 & 0.069 \\
6 months & $21.37 \pm 1.54$ & $21.00 \pm 2.52$ & 28 & 0.638 \\
I2 months & $21.88(2.05)$ & $21.06(2.11)$ & 33 & 0.269
\end{tabular}

Note: *Significance set at $P<0.05$.

Abbreviations: ALT, argon laser trabeculoplasty; SLT, selective laser trabeculoplasty; SD, standard deviation. 


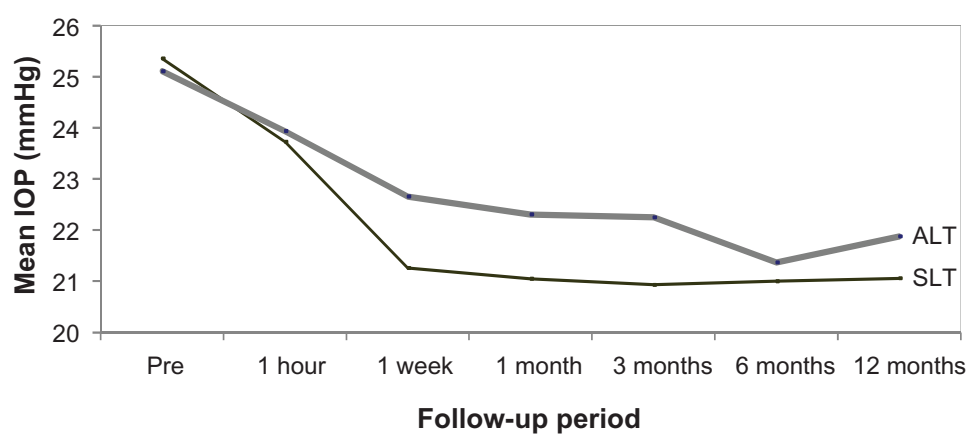

Figure I Change in IOP at various time points.

Abbreviations: IOP, intraocular pressure; Pre, pretreatment; ALT, argon laser trabeculoplasty; SLT, selective laser trabeculoplasty.

the criterion for surgical success, there was a clear advantage for the SLT-treated patients.

A total of 15 patients, 12 in the ALT group and three in the SLT group, had an unsatisfactory reduction in IOP after the laser treatment, resulting in failures which led to either adding or changing the type of an IOP-lowering medication, or undergoing either a trabeculectomy or a repeat ALT. Unsatisfactory reduction in IOP was considered when there was a failure to reach the target IOP of the eye based on baseline IOP, clinical evaluation of cup-to-disc ratio and visual field damage, as well as the global indices. The type of treatment used in case of failure was decided based on the IOP and advancement in glaucoma severity. Table 3 summarizes the number of adverse events encountered in each group. Statistical analyses showed no correlations between pigment severity and IOP-lowering potential of the laser treatments.

\section{Discussion}

Several studies have favored SLT over ALT due to a number of benefits, such as targeting only the pigmented TM cells, ${ }^{3}$ low incidence of peripheral anterior synechia formation or collateral damage, and the potential of being a repeatable procedure. ${ }^{4}$ Other studies claimed a clear advantage of ALT over SLT in certain glaucoma types, such as pseudoexfoliation and pigmentary glaucoma. ${ }^{21} \mathrm{~A}$ few investigations compared the IOP-lowering effect of SLT with ALT in various glaucoma types, ${ }^{3,5,7-9,22}$ but, to the best of our knowledge,

Table 3 Number of eyes that sustained adverse events

\begin{tabular}{lll}
\hline Complications & $\begin{array}{l}\text { ALT } \\
(\mathbf{n}=\mathbf{8})\end{array}$ & $\begin{array}{l}\text { SLT } \\
(\mathbf{n}=3)\end{array}$ \\
\hline Trabeculectomy & $8(26.7 \%)$ & $2(9.09 \%)$ \\
Change (addition) to & $3(10 \%)$ & $\mathrm{I}(4.5 \%)$ \\
IOP-lowering medications & & \\
ALT repeated & $\mathrm{I}(3.33 \%)$ & \\
\hline
\end{tabular}

Abbreviations: ALT, argon laser trabeculoplasty; SLT, selective laser trabeculoplasty; IOP, intraocular pressure. the current study is the first to compare the IOP-lowering potential between these two laser approaches in glaucoma patients who recently underwent successful phacoemulsification cataract extraction surgery.

Damji et $\mathrm{al}^{5}$ performed a randomized clinical trial comparing the effect of SLT and ALT over a period of 18 months. Their results demonstrated that the IOP-lowering effect was similar in both groups. Holló ${ }^{22}$ prospectively studied 28 eyes from 14 patients, in which one eye was treated with ALT and the fellow eye with SLT, and the author found no significant difference in the decreasing of IOP potential following either procedure. Juzych et $\mathrm{al}^{8}$ prospectively compared the IOPlowering effect of SLT and ALT in almost 200 eyes with POAG patients over a 5-year follow-up period and found the procedures to be of similar benefit as well. Martinez-dela-Casa et $\mathrm{al}^{9}$ conducted a similar study, and they also found a comparable IOP-lowering effect $(20 \%$ reduction in IOP in the ALT group and $22 \%$ in the SLT group) for the two techniques. Popiela et $\mathrm{al}^{7}$ treated 27 open angle glaucoma patients by ALT in one eye and SLT in the other eye, and they achieved results similar to those of the other studies, with no benefit of one procedure over the other.

The efficacy of ALT in aphakic and pseudophakic eyes was reviewed by Schwartz et al. ${ }^{23}$ They found that eyes that were treated with ALT had a success rate of up to $34 \%$ at 36 months posttreatment. They also found that pseudophakic eyes had a better response rate than aphakic eyes, and that eyes with extracapsular surgery did better than the ones with intracapsular surgery. Werner et $\mathrm{al}^{19}$ retrospectively compared the IOP-lowering effect of SLT in phakic and pseudophakic patients; the mean IOP decreased from 18.1 to $15.5 \mathrm{mmHg}$ in the phakic group, and from 18.3 to $15.2 \mathrm{mmHg}$ in the pseudophakic group. They concluded that there were no significant differences in decreased IOP or success rates between phakic and pseudophakic eyes at any time point during their study. 
A recent study by Shazly et $\mathrm{al}^{24}$ evaluated the IOP-lowering effect of SLT as primary treatment in POAG or OHT phakic patients to POAG or OHT pseudophakic patients in up to 30 months of follow-up. They found the greatest reduction in IOP at 3 months posttreatment, which is what we found in our current study. Their conclusion was that the response to SLT treatment was delayed in the pseudophakic compared to the phakic patients, while the long-term effectiveness of SLT was the same in both groups. It is unclear why SLT may be more effective in pseudophakic patients, but, as suggested by those authors, ${ }^{24}$ it is plausible that clear corneal phacoemulsification and SLT may share a common pathway involving inflammation, prostaglandin release, and interleukin- $1 \alpha$ release. Therefore, the IOP response to SLT may be different in pseudophakic eyes compared to phakic eyes due to partial or complete activation of pathways common to the SLT response and to the clear cornea phacoemulsification mediated IOP-lowering effect in those patients.

\section{Conclusion}

The findings of this study show no significant differences in the IOP-lowering capabilities of ALT and SLT throughout 12 months of follow-up. The biggest differences between the two groups were evident at 1 week and 3 months posttreatment, but none reached a level of significance. Only the SLT group had surgical success, which was defined by achieving the study's target of a mean IOP reduction from baseline of $\geq 15 \%$; the reduction in IOP was $16.9 \%$ in the SLT group, as compared to $12.8 \%$ in the ALT group. Overall, both laser techniques acceptably reduced the IOP from baseline until study closure at 12 months, and both were safe and effective for treating various types of glaucomas in our study population.

\section{Disclosure}

The authors report no conflicts of interest in this work. The authors have not received any grant support or research funding, and do not have any proprietary interests in the materials described in the article. The manuscript was not presented at any meetings.

\section{References}

1. Wise JB, Witter SL. Argon laser therapy for open-angle glaucoma. Arch Ophthalmol. 1979;97(2):319-322.

2. Latina MA, Park C. Selective targeting of trabecular meshwork cells: in vitro studies of pulsed and CW laser interactions. Exp Eye Res. 1995; 60(4):359-371.

3. Anderson RR, Parrish JA. Selective photothermolysis: precise microsurgery by selective absorption of pulsed radiation. Science. 1983;220(4596): 524-527.
4. Kramer TR, Noecker RJ. Comparison of the morphologic changes after selective laser trabeculoplasty and argon laser trabeculoplasty in human eye bank eyes. Ophthalmology. 2001;108:773-779.

5. Damji KF, Shah KC, Rock WJ, Bains HS, Hodge WG. Selective laser trabeculoplasty $\mathrm{v}$ argon laser trabeculoplasty: a prospective randomised clinical trial. Br J Ophthalmol. 1999;83(6):718-722.

6. Hodge WG, Damji KF, Rock W, Buhrmann R, Bovell AM, Pan Y. Baseline IOP predicts selective laser trabeculoplasty success at 1 year post-treatment: results from a randomised clinical trial. $\mathrm{Br} J$ Ophthalmol. 2005;89(9):1157-1160.

7. Popiela G, Muzyka M, Szelepin L, Cwirko M, Nizankowska MH. Use of YAG-Selecta laser and argon laser in the treatment of open angle glaucoma. Klin Oczna. 2000;102(2):129-133. Polish.

8. Juzych MS, Chopra V, Banitt MR, et al. Comparison of long-term outcomes of selective laser trabeculoplasty versus argon laser trabeculoplasty in open-angle glaucoma. Ophthalmology. 2004;111(10): 1853-1859.

9. Martinez-de-la-Casa JM, Garcia-Feijoo J, Castillo A, et al. Selective vs argon laser trabeculoplasty: hypotensive efficacy, anterior chamber inflammation, and postoperative pain. Eye (Lond). 2004;18(5): 498-502.

10. Pirnazar JR, Kolker A, Wax M, et al. The efficacy of $532 \mathrm{~nm}$ laser trabeculoplasty. Invest Ophthalmol Vis Sci. 1998;39:S5.

11. Tabak S, de Waad PWT, Lermij HG, et al. Selective laser trabeculoplasty in glaucoma. Invest Ophthalmol Vis Sci. 1998;39:S472.

12. Bhallil S, Andalloussi IB, Chraibi F, Daoudi K, Tahri H. Changes in intraocular pressure after clear corneal phacoemulsification in normal patients. Oman J Ophthalmol. 2009;2(3):111-113.

13. Hansen TE, Naeser K, Rask KL. A prospective study of intraocular pressure four months after extracapsular cataract extraction with implantation of posterior chamber lenses. J Cataract Refract Surg. 1987;13(1):35-38.

14. Saccà $\mathrm{S}$, Marletta $\mathrm{A}$, Pascotto $\mathrm{A}$, et al. Daily tonometric curves after cataract surgery. Br J Ophthalmol. 2001;85(1):24-29.

15. Tanaka T, Inoue H, Kudo S, Ogawa T. Relationship between postoperative intraocular pressure elevation and residual sodium hyaluronate following phacoemulsification and aspiration. J Cataract Refract Surg. 1997;23(2):284-288.

16. Issa SA, Pacheco J, Mahmood U, Nolan J, Beatty S. A novel index for predicting intraocular pressure reduction following cataract surgery. Br J Ophthalmol. 2005;89(5):543-546.

17. Mathalone N, Hyams M, Neiman S, Buckman G, Hod Y, Geyer O. Long-term intraocular pressure control after clear corneal phacoemulsification in glaucoma patients. J Cataract Refract Surg. 2005;31(3): 479-483.

18. Pohjalainen T, Vesti E, Uusitalo RJ, Laatikainen L. Phacoemulsification and intraocular lens implantation in eyes with open-angle glaucoma. Acta Ophthalmol Scand. 2001;79(3):313-316.

19. Werner M, Smith MF, Doyle JW. Selective laser trabeculoplasty in phakic and pseudophakic eyes. Ophthalmic Surg Lasers Imaging. 2007; 38(3):182-188.

20. Huang G, Gonzalez E, Peng PH, et al. Anterior chamber depth, iridocorneal angle width, and intraocular pressure changes after phacoemulsification: narrow vs open iridocorneal angles. Arch Ophthalmol. 2011; 129(10):1283-1290.

21. [No authors listed]. The Glaucoma Laser Trail (GLT). 2. Results of argon laser trabeculoplasty versus topical medicines. The Glaucoma Laser Trial Research Group. Ophthalmology. 1995;120(6):718-731.

22. Holló G. Argon and low energy, pulsed Nd:YAG laser trabeculoplasty. A prospective, comparative clinical and morphological study. Acta Ophthalmol Scand. 1996;74(2):126-131.

23. Schwartz AL, Wilson MC, Schwartz LW. Efficacy of argon laser trabeculoplasty in aphakic and pseudophakic eyes. Ophthalmic Surg Lasers. 1997;28(3):215-218.

24. Shazly TA, Latina MA, Dagianis JJ, Chitturi S. Effect of prior cataract surgery on the long-term outcome of selective laser trabeculoplasty. Clin Ophthalmol. 2011;5:377-380. 


\section{Publish your work in this journal}

Clinical Ophthalmology is an international, peer-reviewed journal covering all subspecialties within ophthalmology. Key topics include: Optometry; Visual science; Pharmacology and drug therapy in eye diseases; Basic Sciences; Primary and Secondary eye care; Patient Safety and Quality of Care Improvements. This journal is indexed on
PubMed Central and CAS, and is the official journal of The Society of Clinical Ophthalmology (SCO). The manuscript management system is completely online and includes a very quick and fair peer-review system, which is all easy to use. Visit http://www.dovepress.com/ testimonials.php to read real quotes from published authors. 